\title{
Avaliação hematológica seriada de cordeiros das raças Santa Inês e Dorper
}

Claudijane de Carvalho Matos', Edson Moura da Silva, Bruna Catarina de O. Feitosa, Deivisson Felix da Silva, Bruno de Assis Cavalcante,Adrianne Mota de Alcantara, Kelly Cunha Vital, Karina Pessoa de Oliveira, Márcia Kikuyo Notomi,Diogo Ribeiro Câmara

Universidade Federal de Alagoas (UFAL), Maceió, AL, Brasil

*Autor correspondente

e-mail: claudijanematos@gmail.com

\section{Resumo}

A ovinocultura é de importância socioeconômica crescente no Brasil, tendo a carne de carneiro uma ascensão na demanda do consumo e lucratividade proporcional. Contudo, há poucos estudos relacionados ao uso do hemograma para a avaliação dessa espécie, agravando-se no caso de cordeiros. Objetivou-se diferenciar valores de hemogramas e proteínas plasmáticas totais (PPT) em cordeiros das raças Santa Inês e Dopper, em diferentes intervalos de tempo, sendo avaliados 30 ovinos hígidos, de 21-30 dias de idade, sendo 16 da raça Santa Inês e 14 da raça Dopper, provenientes da Fazenda São Luiz, da cidade de Viçosa, Alagoas. Com os animais em jejum, foram coletados 5,0 mL de sangue via jugular, sendo este acondicionado em tubo com EDTA. As análises hematológicas consistiram na mensuração de volume globular (VG \%) pela técnica de microhematócrito, contagem total de leucócitos em câmara de hematimétrica (Neubauer), contagem diferencial leucocitária em esfregaço sanguíneo corado e concentração de proteína total plasmática (PPT) por refratometria. As amostras foram coletadas em sete tempos, com intervalo de 15 dias, com os cordeiros com 30, 45, 60, 75, 90, 105 e 120 dias de idade. Uma análise estatística descritiva foi realizada para os diferentes tempos e a diferença entre eles foi obtida através da comparação pelo teste de Tukey. Os valores observados encontravam-se dentro dos valores de referência para um animal adulto. Semelhante a afirmações de Schmidt et al. (2001), o volume globular teve um significativo aumento $(\mathrm{P}<0,01)$ em 120 dias quando comparado com os outros tempos, que não diferiram entre si, existindo aumento dos parâmetros sanguíneos de acordo com o desenvolvimento etário, bem como a maturação do sistema hematopoiético. As concentrações da proteína total plasmática, apesar da ausência de variação significativa, apresentaramse discretamente inferiores ou no limite inferior de normalidade quando comparadas com a concentração de animais adultos. De acordo com Schmidt et al. (2001), essa concentração é baixa nos animais recémnascidos e aumenta gradualmente até alcançar a variação normal a partir dos 6 meses de idade. Não foram observadas diferenças significativas entre os tempos nos números de leucócitos totais, neutrófilos 
segmentados, linfócitos e monócitos, porém observou-se um aumento gradativo no número de linfócitos de 30 a 105 dias, assim como o estudo de Schmidt et al. (2001). Semelhantemente a Souza et al. (2012) e Jones e Allison (2007), os neutrófilos bastonetes e basófilos apresentaram pequenas variações e baixas contagens nos diferentes tempos. Portanto, conclui-se que cordeiros com 120 dias apresentam um maior volume globular do que cordeiros com menor idade, porém sem alterações no número de leucócitos. Observou-se, também, que animais entre 30 e 120 dias apresentam uma menor concentração de proteína plasmática total quando comparados a animais adultos. 